\title{
Perfil tecnológico de acadêmicos de cursos de licenciatura das ciências da natureza
}

\author{
Silvio Luiz Rutz da Silva \\ Patrícia Sattin Garrouba Biégas \\ Jéssica da Silva Gaudêncio \\ Daniela Mayer Antunes \\ Alan Vaz Mainardes \\ Leticia Polli Glugoski
}

\begin{abstract}
Resumo
Neste trabalho apresentamos o resultado de levantamento do perfil tecnológico de acadêmicos dos cursos de licenciatura em biologia, geografia, química e física da Universidade Estadual de Ponta Grossa, a partir de investigação de como os mesmos utilizam os equipamentos tecnológicos que atualmente fazem parte do cotidiano da maioria das pessoas, como celulares, computadores de mesa, computadores portáteis e tablets. Participaram da pesquisa 120 estudantes, sendo 20 do curso de Física, 30 do curso de Química, 30 do curso de Biologia e 40 do curso de Geografia. A análise dos questionários mostra que $98 \%$ tem acesso a internet, sendo que o celular e o notebook são os principais equipamentos utilizados. O principal uso do celular é atividades diversas e os tablets para estudar e atividades diversas. Os PCs são usados para estudo e os notebooks para estudo, assim como para preparar aulas. $92,5 \%$ dos entrevistados tem conta nas redes sociais, sendo predominante o Facebook (90,4 \%). Entretanto apenas $17,9 \%$ responderam que fazem uso das TICs para atividades de ensino aprendizagem. Outro fator indicado é que $32 \%$ apenas já utilizou aplicativos educacionais e que $34,6 \%$ já desenvolveu alguma atividade educacional com o uso de computadores. Os resultados mostram que os futuros professores têm acesso amplo aos recursos tecnológicos, entretanto não os utilizam nas suas atividades de aprendizagem o que indica de maneira indireta que os cursos de Licenciatura não têm levado em conta o potencial das TICs no processo de ensino aprendizagem.
\end{abstract}

Palavras-chave: Ensino; Tecnologia; Ciência Naturais; TICs.

Abstract
Technological profile of academic degree courses of the Sciences of
nature.
In this work we present the result of lifting the technological profile of the
courses of academic degree in biology, geography, chemistry and physics at the
State University of Ponta Grossa, from investigation of how the same using the
technological equipment that currently are part of the everyday life of most
people, such as cell phones, desktops, laptops and tablets. 120 students
participated in the research, being the Physical course 20 , course 30 , Chemistry 30
course of biology and Geography course 40 . The analysis of questionnaires shows

R. B. E. C. T., vol 7, núm. 3, set-dez.2014 ISSN - 1982-873X

DOI: Em andamento. 
that $98 \%$ have access to the internet; the phone and the laptop are the main equipment used. The main use of the phone is various activities and the tablets to study and various activities. The PCs are used to study and the notebooks for study, as well as to prepare lessons. $92.5 \%$ of respondents have an account on social networks, being predominantly Facebook (90.4 percent). However only $17.9 \%$ responded that make use of ICTs for educational learning activities. Another factor indicated is that $32 \%$ only has already used educational applications and $34.6 \%$ have already developed some educational activity with the use of computers. The results show that student teachers have ample access to technological resources, however do not use them in their learning activities that indirectly indicates that undergraduate courses are not take into account the potential of ICTs in the teaching learning process.

Keywords: Teaching, Technology; Natural Science; CITs.

\section{Introdução}

Muitas são as transformações sociais, culturais e educacionais de nosso tempo, principalmente com relação às mudanças nas diferentes instituições socializadoras que fazem parte da nossa vida cotidiana e que influenciam a constituição do novo homem e condicionam a forma como pensa sobre si mesmo e suas relações com seus semelhantes.

Este trabalho fundamenta-se em uma abordagem interdisciplinar do uso de objetos de aprendizagem, recursos digitais e virtuais para o ensino de ciências da natureza, buscando uma reflexão para desvendar e introduzir novos enfoques e experiências. Esta abordagem interdisciplinar baseia-se no fato de que a separação em disciplinas (física, química, biologia e geografia) no ensino das ciências da natureza é artificial, levando a uma compreensão errônea acerca da construção do conhecimento científico (POMBO; 2011, CANIATO; 2011).

Uma abordagem interdisciplinar deve contemplar aspectos relativos às ciências da natureza de modo integrado entre as áreas da química, geociências, física e biologia de modo a se produzir um ensino mais próximo dos estudantes e mais preocupado com a ampliação da cultura científica (CANIATO; 2011, INFANTE-MALACHIAS; 2011, VILLANI e MELGAÇO; 2011).

Observando-se o ensino de ciências da natureza por esta perspectiva surge a questão: Como a escola e os professores devem se posicionar frente a esta nova contextualização que pressupõe uma relação ativa, produtora? Isto decorre do fato de que aprendemos nos diversos ambientes que circulamos. Tal falto leva a pressupor que é necessário dispor conhecimentos relacionados aos mais diversos meios de produção e disseminação desses conhecimentos. Nesse processo ganha cada vez mais importância o domínio de ferramentas tecnológicas dependentes, especialmente de recursos computacionais, aos quais nos referimos como tecnologias de informação e comunicação (TICS).

Pesquisas recentes relativas às novas mídias indicam que os espaços das tecnologias de informação e comunicação (TICS) como a internet devem ser vistos como um novo meio de 
expressão, concebido como veículo de diálogo e trocas comunicativas intensas e como espaço de construção de novas amizades, sociabilidade e reflexibilidade. É compreendido também como um local de tolerância e liberdade de expressão para os quais se cria e produz conteúdos destinados aos receptores dessa nova linguagem.

Esses espaços são responsáveis por uma nova forma de escrita e de percepção do tempo e do espaço, constituindo-se em formas inéditas de organizar e representar ideias, pensamentos e fantasias (ALMEIDA; 2001, CAXIAS, 2008, PORTO; 2006).

Neste trabalho considera-se que esses recursos tecnológicos são pedagógicos ou educativos, porque o indivíduo passa a ter autoria na sua produção, e sente-se estimulado a produzir, escrever e ler a produção dos outros. Estas tecnologias têm um potencial incomensurável de formação e de reconstrução de experiências indenitárias, nesse sentido o usuário das novas mídias passa a ser reconhecido como um sujeito criativo em potencial. Assim é preciso analisar o processo educativo atual considerando a construção das identidades sociais e culturais mediadas pelas distintas matrizes midiáticas. Isto conduz a um novo modo de encarar a Ciência como uma atividade cotidiana especialmente para professores: surge assim a perspectiva da Ciência Pública e ou Ciência Social.

O objetivo desta pesquisa foi de contabilizar o número de acadêmicos que possuem acesso à internet e, a partir disso, saber quantos deles possuem contas nas mais diferentes redes sociais e se fazem uso das mesmas para assuntos voltados ao aprendizado ou se as mesmas apenas são utilizadas como um meio de entretenimento, tendo com resultado o levantamento do perfil tecnológico dos estudantes.

Pretende-se, também, contribuir com a reflexão sobre os desafios da educação contemporânea e da educação midiática na formação das novas gerações, a partir da avaliação do uso das mídias na formação dos professores de ciências, uma vez que as redes sociais apresentam-se como excelente ferramenta para a educação, já que oferecem ao educando diferentes possibilidades para trocas de informações e conhecimento.

\section{Metodologia}

Neste trabalho apresentamos o resultado de pesquisa realizada com acadêmicos de licenciatura da área de ciências da natureza da Universidade Estadual de Ponta Grossa para levantar o perfil de uso de recursos tecnológicos dos licenciandos, buscando visualizar como os mesmos utilizam os equipamentos tecnológicos e seus recursos que atualmente fazem parte do cotidiano da maioria das pessoas e as possibilidades de relacionamento por meio desses recursos que podem ser utilizados no processo de ensino-aprendizagem. 
A pesquisa foi realizada no ano de 2013 com a aplicação de um questionário, baseado em Tajra (2008; p. 80-104). Participaram da pesquisa 120 estudantes de licenciatura, sendo 20 de física, 30 de química, 30 de biologia e 40 de geografia. As perguntas presentes no questionário foram relacionadas ao emprego de equipamentos tais como aparelhos celulares, computadores de mesa, computadores portáteis e tablets de modo a investigar a forma com que os acadêmicos fazem uso desses recursos nas suas atividades de estudo e ou lazer.

Além desse aspecto os estudantes foram questionados se já atuam na docência e em caso positivo quais disciplinas ministram; se já fizeram curso de informática ou de uso de mídias e recursos computacionais no ensino; se já utilizou aplicativos educacionais e quais foram; se já planejou atividades didáticas ou projeto de ensino com o uso de computadores; quais os tipos de equipamentos eletrônicos possui e qual o uso faz desses; se tem acesso a internet e em que local; se tem conta nas redes sociais e se as utilizou em atividades educacionais; e qual sistema de buscas usa para realizar pesquisas na internet. Os dados foram contabilizados e os resultados apresentados e discutidos a seguir.

\section{Resultados}

Os equipamentos tecnológicos eletrônicos representam um importante recurso para a Educação, podendo em determinadas circunstâncias, fazer com que o processo de ensinoaprendizagem seja mais efetivo. Atualmente existe um número significativo de textos que abordam do uso das tecnologias nas salas de aula, sejam elas da educação básica ou de nível superior, entretanto frequentemente se indaga se o futuro profissional da educação está ciente de como esses recursos podem ser utilizados para a melhoria do processo de ensinoaprendizagem. Também tem-se clareza de que na Universidade, situa-se o lócus para essa formação, a partir da possibilidade de atividades de aprendizagem que integrem tais perspectivas. Nesse momento essa tarefa torna-se mais fácil de ser realizada porque o esse aluno em formação lida com esses recursos nas mais diversas atividades cotidianas.

A seguir apresenta-se os resultados obtidos para as questões propostas para o levantamento do perfil tecnológico dos alunos de licenciatura na área das ciências naturais.

Na figura 1, apresenta-se o resultado da questão se os acadêmicos dos cursos já exercem à docência, sendo que em média $11,9 \%$ dos alunos já atuam como docentes e $9 \%$ atuam na disciplina de sua formação. Em biologia 6,7 \% dos alunos já são docentes, em física10 \%, em geografia $7,5 \%$ e em química $23,3 \%$. 3,3 \% dos alunos de biologia ministram a disciplina equivalente ao curso em que estão em formação; para física são 10 \%, para geografia 2,5 \% e para química $20 \%$. 


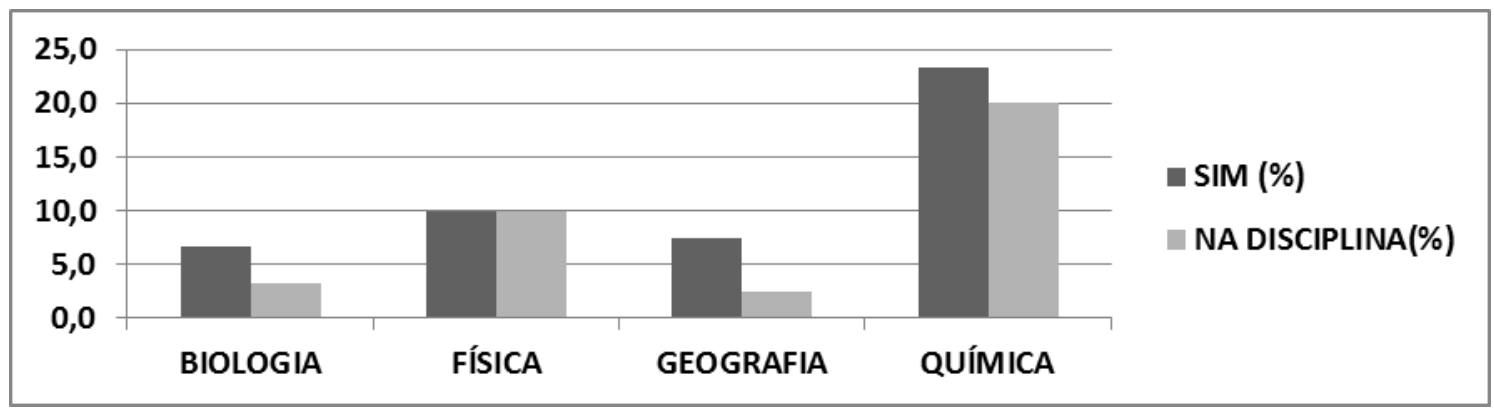

Figura 1 - Proporção de acadêmicos que já exercem a docência, se na mesma disciplina de formação.

Na figura 2 apresenta-se o resultado de duas questões: em 2a, se os alunos fizeram curso na área de informática; e em $2 \mathrm{~b}$ se fizeram algum curso de usos de mídias ou recursos virtuais no ensino. Os resultados indicam que $71,9 \%$ já fizeram um curso de informática e que $16,7 \%$ fizeram algum curso de mídias aplicadas ao ensino. Especificamente por curso temos que a proporção de acadêmicos que já fez curso de informática é de 70,0 \%, 50,0 \%, 77,5 \% e $90 \%$, respectivamente para biologia, física, geografia e química. Para a questão, se fez curso de usos de mídias no ensino a proporção é de $30 \%, 26,7$ \% e $10 \%$ para biologia, geografia e química respectivamente.

$\mathrm{Na}$ figura 3 verifica-se que a proporção média de alunos que já usou aplicativos educacionais é de 32 \%. Por sua vez, mais especificamente, a proporção para acadêmicos de biologia é de $23,3 \%$, de física de $45 \%$, de geografia de $40 \%$ e de química de $20 \%$.
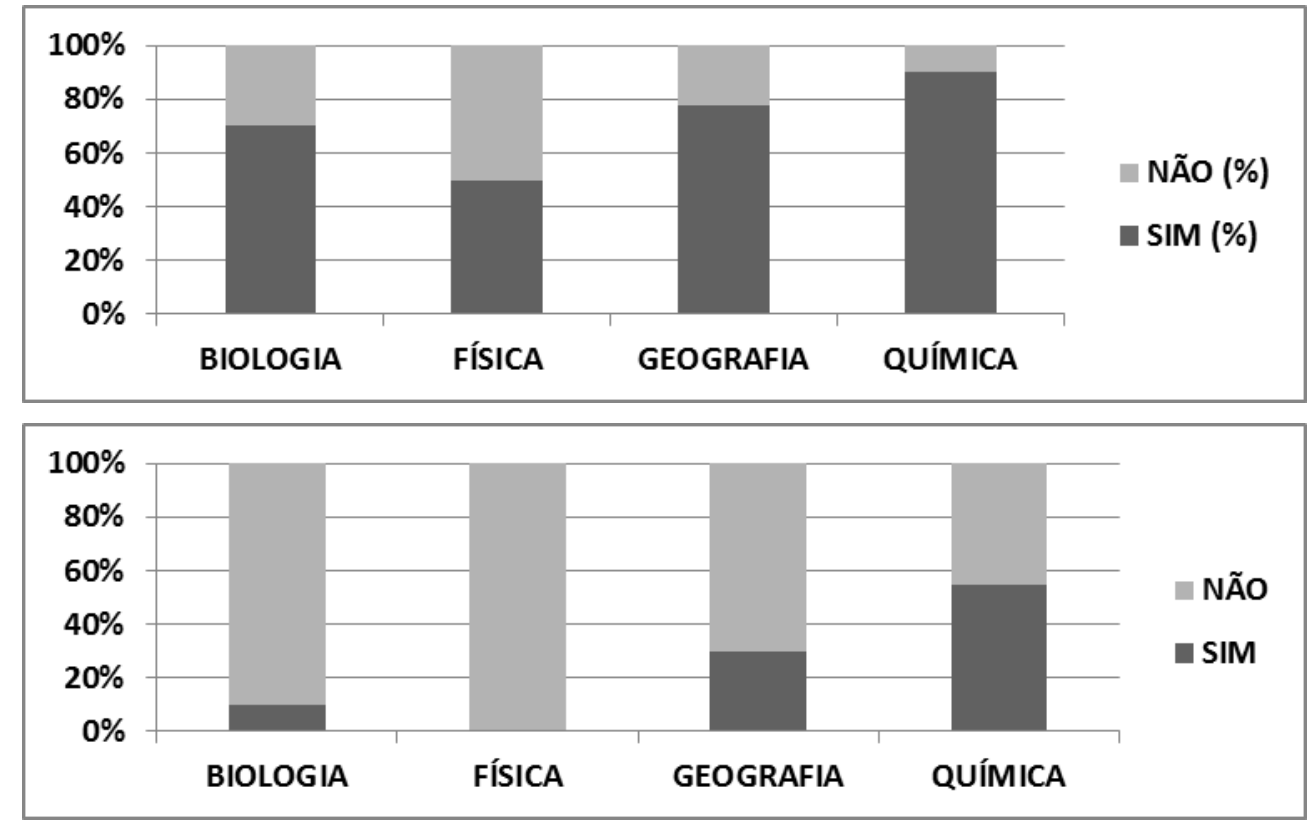

b

Figura 2 - Proporção de alunos que: a) fez curso de informática;

b) fez curso de mídias no ensino.

DOI: Em andamento. 


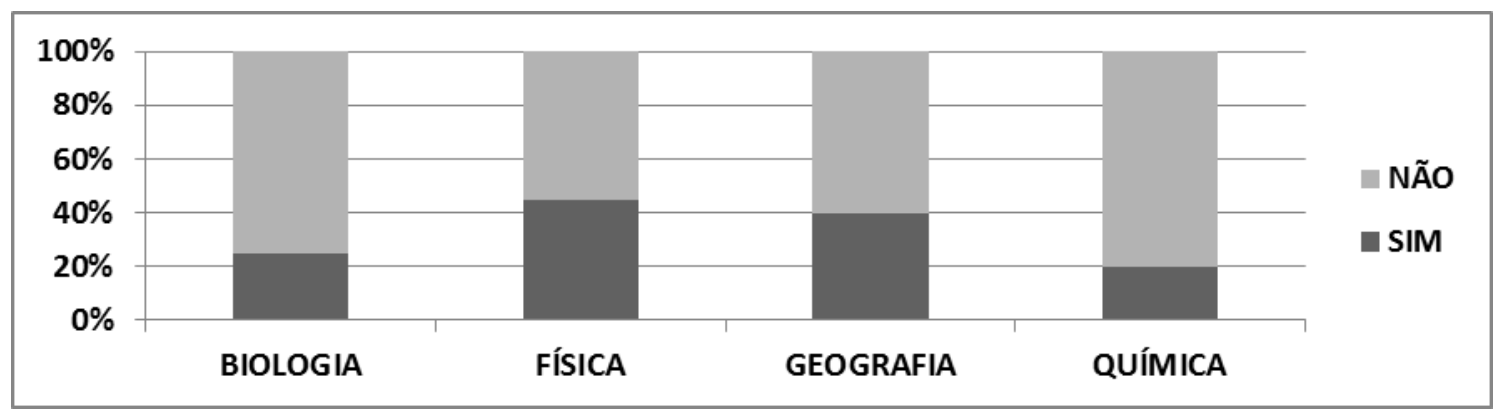

Figura 3 - Proporção de alunos usou aplicativos educacionais.

Pela figura 4 temos a proporção média de alunos que já desenvolveu alguma aula ou projeto educacional com o uso de computadores corresponde a $34,6 \%$. Por curso temos $36,7 \%$, $30 \%, 35 \%$ e 36,7 \% para biologia, física, geografia e química respectivamente.

Na tabela 1 são apresentados os tipos de equipamentos que os alunos possuem sendo que o celular e o notebook são os equipamentos mais utilizados $(82,8$ \% e $82,7 \%$ respectivamente). Os Tablets correspondem a 19,8 \% enquanto os PCs representam 67,2 \%. Estas variações tem a mesma tendência para todos os cursos.

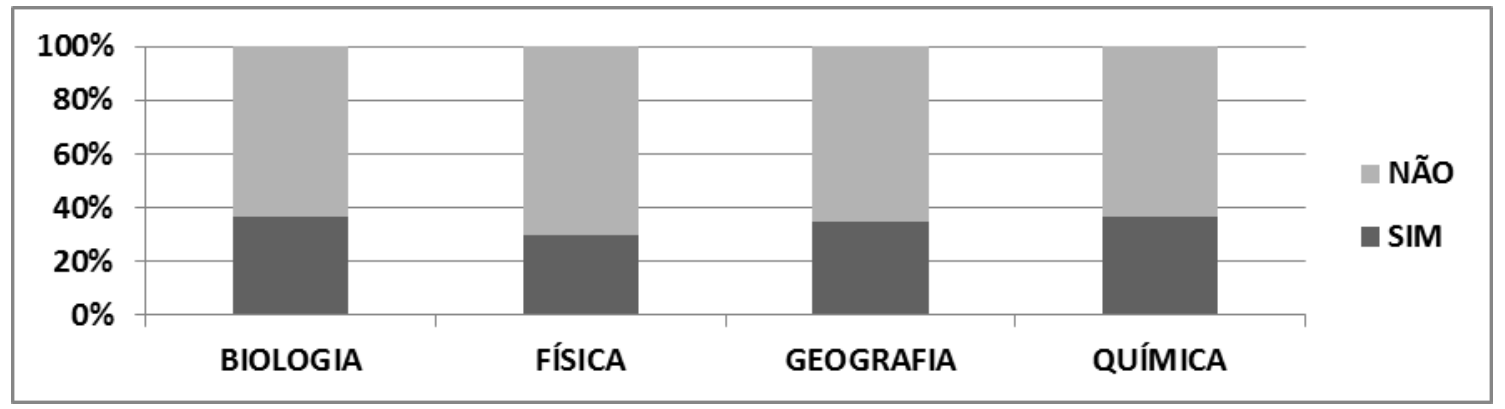

Figura 4 - Proporção de alunos que já desenvolveu alguma aula ou projeto educacional com o uso de computadores.

Tabela 1 - Tipos de equipamentos mais utilizados

\begin{tabular}{lccccc} 
Equipamento que possui (\%) & Biologia & Física & Geografia & Química & Média \\
\hline $\begin{array}{l}\text { Celular-smartfone } \\
\text { Tablet (ipad, galaxy, ou }\end{array}$ & 90,0 & 90,0 & 80,0 & 83,3 & 82,8 \\
equivalente) & 6,7 & 35,0 & 17,5 & 20,0 & 19,8 \\
PC (computador de mesa) & 64,0 & 55,0 & 86,6 & 63,3 & 67,2 \\
Notebook ou netbook & 90,0 & 75,0 & 82,5 & 83,3 & 82,7
\end{tabular}


Por sua vez na tabela 2 estão indicados quais são os sistemas operacionais e aplicativos mais conhecidos. O sistema operacional mais amplamente empregado é o Windows ${ }^{\circledR}$ com proporção média de uso de $98,3 \%$. Os aplicativos mais utilizados são: power point ${ }^{\circledR}$, navegadores internet, word ${ }^{\circledast}$, excell ${ }^{\circledast}$ e outros pacotes office. Ainda, aplicativos educacionais são conhecidos por $45,0 \%$ dos acadêmicos sendo indicados por $30 \%, 55 \%, 65 \%$ e $30 \%$ dos alunos dos cursos de biologia, física, geografia e química, respectivamente.

Na tabela 3 está indicado qual a finalidade de uso dos equipamentos. Para os celulares e smartfones temos que 27,9 \% utiliza para jogos, 32,5\% para estudar e pesquisar, 5,2 \% para preparar aulas e 70,8 \% para outras atividades. Os tablets são utilizados por 9,2 \% para jogos, 14,9 \% para estudar e pesquisar, 5 \% para preparar aulas e 11,7 \% para outras atividades. Os PCs são utilizados para jogos por $21,8 \%$, para estudar e pesquisar por $56,9 \%$, para preparar aulas por $28,5 \%$ e para outras atividades por $42,9 \%$. Os notebooks são utilizados para jogos por $32,6 \%$, par estudar ou pesquisar por $75,2 \%$, para preparar aulas por $44,6 \%$ e por $51,5 \%$ para outras atividades.

Tabela 2 - Sistemas operacionais e aplicativos mais conhecidos.

\begin{tabular}{|c|c|c|c|c|c|}
\hline Citações (\%) & Biologia & Física & Geografia & Química & Média \\
\hline Windows & 100,0 & 100,0 & 100,0 & 93,3 & 98,3 \\
\hline $\begin{array}{l}\text { Outros sistemas operacionais } \\
\left(\text { apple }^{\circledR}, \text { linux }^{\circledR}\right)\end{array}$ & 53,3 & 65,0 & 65,0 & 73,3 & 64,1 \\
\hline $\begin{array}{l}\text { Word } 97^{\circledR} \text { ou outras versões mais } \\
\text { atualizadas }\end{array}$ & 90,0 & 80,0 & 80,0 & 76,7 & 81,7 \\
\hline $\begin{array}{l}\text { Excel } 97^{\circledR} \text { ou outras versões mais } \\
\text { atualizadas }\end{array}$ & 80,0 & 80,0 & 82,5 & 80,0 & 80,6 \\
\hline Power point $^{\circledR}$ & 100,0 & 100,0 & 90,0 & 100,0 & 97,5 \\
\hline $\begin{array}{l}\text { Outros pacotes office (openoffice } \\
\text { ou equivalentes) }\end{array}$ & 40,0 & 55,0 & 60,0 & 43,3 & 49,6 \\
\hline 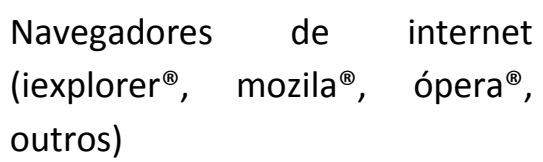 & 96,7 & 100,0 & 90,0 & 90,0 & 94,2 \\
\hline Softwares educacionais & 30,0 & 55,0 & 65,0 & 30,0 & 45,0 \\
\hline
\end{tabular}


Tabela 3 - Principais usos dos equipamentos.

Finalidade de uso do equipamento (\%)

\begin{tabular}{|c|c|c|c|c|c|}
\hline & Biologia & Física & Geografia & Química & Média \\
\hline \multicolumn{6}{|c|}{ Celular - smartfone } \\
\hline Jogos & 33,3 & 15,0 & 30,0 & 33,3 & 27,9 \\
\hline Estudar / pesquisar & 53,3 & 35,0 & 15,0 & 26,7 & 32,5 \\
\hline Preparar aulas & 3,3 & 0,0 & 7,5 & 10,0 & 5,2 \\
\hline Outros & 73,3 & 70,0 & 70,0 & 70,0 & 70,8 \\
\hline \multicolumn{6}{|c|}{ Tablet (ipad, galaxy, ou equivalente) } \\
\hline Jogos & 0,0 & 15,0 & 15,0 & 6,7 & 9,2 \\
\hline Estudar / pesquisar & 0,0 & 25,0 & 12,5 & 22,2 & 14,9 \\
\hline Preparar aulas & 0,0 & 5,0 & 5,0 & 10,0 & 5,0 \\
\hline Outros & 6,7 & 10,0 & 17,5 & 13,3 & 11,7 \\
\hline \multicolumn{6}{|c|}{ PC (computador de mesa) } \\
\hline Jogos & 16,6 & 20,0 & 47,5 & 13,3 & 21,8 \\
\hline Estudar / pesquisar & 60,0 & 55,0 & 60,0 & 63,3 & 59,6 \\
\hline Preparar aulas & 23,3 & 20,0 & 47,5 & 23,3 & 28,5 \\
\hline Outros & 40,0 & 30,0 & 55,0 & 46,7 & 42,9 \\
\hline \multicolumn{6}{|c|}{ Notebook ou netbook } \\
\hline Jogos & 23,3 & 40 & 45,0 & 22,2 & 32,6 \\
\hline Estudar / pesquisar & 83,3 & 70 & 67,5 & 80,0 & 75,2 \\
\hline Preparar aulas & 40,0 & 35 & 60,0 & 43,3 & 44,6 \\
\hline Outros & 53,3 & 25 & 67,5 & 60,0 & 51,5 \\
\hline
\end{tabular}

$\mathrm{Na}$ tabela 4 são indicados os dados relativos às redes sociais, assim como quais são as mais utilizadas. Dos entrevistados 92,5 \% têm conta nas redes sociais, sendo a mais utilizada o facebook ${ }^{\circledast}$ com $90,4 \%$, seguido de google $+^{\oplus} \operatorname{com}^{39,6} \%$ e twitter ${ }^{\oplus}$ com $32,7 \%$. Ainda são citados linkedin ${ }^{\circledast}$, instagram ${ }^{\circledR}$ e orkut ${ }^{\circledR}$. Outras redes sociais correspondem a $17,5 \%$.

Tabela 4 - Principais usos dos equipamentos.

\begin{tabular}{|c|c|c|c|c|c|}
\hline Tem conta em redes sociais (\%) & Biologia & Física & Geografia & Química & Média \\
\hline Sim & 96,7 & 95 & 85 & 93,3 & 95,5 \\
\hline Não & 3,3 & 5 & 15 & 6,7 & 7,5 \\
\hline Twitter $^{\circledR}$ & 26,7 & 35 & 42,5 & 26,7 & 32,7 \\
\hline Facebook $^{\circledR}$ & 93,3 & 95 & 80 & 93,3 & 90,4 \\
\hline Google $+^{\circledR}$ & 36,7 & 45 & 30 & 46,7 & 39,6 \\
\hline Linkedin ${ }^{\circledR}$ & 3,3 & 0 & 5 & 6,7 & 15 \\
\hline Instagram $^{\circledR}$ & 13,3 & 10 & 7,5 & 10 & 10,2 \\
\hline Orkut $^{\circledast}$ & 20 & 20 & 32,5 & 13,3 & 21,5 \\
\hline Outras & 13,3 & 20 & 10 & 26,7 & 17,5 \\
\hline
\end{tabular}


$\mathrm{Na}$ tabela 5 está indicado se os alunos já utilizaram as redes sociais em atividades educacionais, sendo que indicaram que $\operatorname{sim} 17,8 \%$.

Tabela 5 - Uso de redes sociais em atividades educacionais.

\begin{tabular}{lccccc}
$\begin{array}{l}\text { Usou redes sociais em atividades } \\
\text { educacionais (\%) }\end{array}$ & Biologia & Física & Geografia & Química & Média \\
\hline Sim & 13,3 & 25,0 & 10,0 & 23,3 & 17,9 \\
Não & 83,3 & 75,0 & 90,0 & 76,7 & 81,2 \\
Sem Resposta & 3,3 & 0,0 & 0,0 & 0,0 & 0,8
\end{tabular}

Na tabela 6 são indicados quais aplicativos mais conhecidos em ordem de ocorrência. Destacam-se o google maps ${ }^{\circledR}$ com $95,4 \%$ e o google ${ }^{\circledR}$ com $91,7 \%$.

Tabela 6-Aplicativos mais conhecidos.

\begin{tabular}{|c|c|c|c|c|c|}
\hline Conhece o aplicativo (\%) & Biologia & Física & Geografia & Química & Média \\
\hline Google maps $^{\circledR}$ & 93,3 & 100,0 & 95,0 & 93,3 & 95,4 \\
\hline Google ${ }^{\circledR}$ & 66,7 & 100,0 & 100,0 & 100,0 & 91,7 \\
\hline Google earth $^{\circledR}$ & 93,3 & 90,0 & 77,5 & 76,7 & 84,4 \\
\hline Skype ${ }^{\circledR}$ & 73,3 & 85,0 & 77,5 & 73,3 & 78,1 \\
\hline Climatempo ${ }^{\circledR}$ & 70,0 & 65,0 & 70,0 & 63,3 & 67,1 \\
\hline Messenger ${ }^{\circledast}$ & 83,3 & 80,0 & 90,0 & 93,3 & 66,4 \\
\hline Google docs ${ }^{\circledR}$ & 33,3 & 50,0 & 52,5 & 60,0 & 48,9 \\
\hline Prezi $^{\circledR}$ & 46,7 & 40,0 & 60,0 & 13,3 & 40,0 \\
\hline Dropbox $^{\circledR}$ & 13,3 & 40,0 & 17,5 & 16,7 & 21,9 \\
\hline $\operatorname{Vimeo}^{\circledR}$ & 3,3 & 0,0 & 17,5 & 6,7 & 6,9 \\
\hline Accuweather ${ }^{\circledR}$ & 10,0 & 5,0 & 5,0 & 0,0 & 5,0 \\
\hline Flipboard $^{\circledR}$ & 0,0 & 5,0 & 2,5 & 6,7 & 3,6 \\
\hline Tune wiki ${ }^{\circledR}$ & 0,0 & 0,0 & 5,0 & 0,0 & 1,3 \\
\hline Tunein $^{\circledR}$ & 0,0 & 0,0 & 5,0 & 0,0 & 1,3 \\
\hline Flud $^{\circledR}$ & 0,0 & 0,0 & 2,5 & 0,0 & 0,6 \\
\hline
\end{tabular}

\section{Análise}

A análise dos questionários mostra que $98 \%$ dos alunos tem acesso a internet, sendo que o celular e o notebook são os principais equipamentos utilizados. O principal uso do celular é para atividades diversas (70,8 \%). Os tablets são utilizados para estudar e atividades diversas (14,9 \% e 11,7 \% respectivamente). Os PCs são usados para estudo por 59,6 \% dos alunos. Os notebooks são os equipamentos mais empregados para estudo $(75,2 \%)$, assim como para preparar aulas $(44,6$ $\%)$. Os alunos que participaram deste estudo na grande maioria têm conta nas redes sociais $(92,5$

DOI: Em andamento. 
$\%)$, sendo predominante o Facebook (90,4 \%). Entretanto apenas $17,9 \%$ responderam que fazem uso das redes sociais para atividades de ensino-aprendizagem. Outro fator indicado é que $32 \%$ apenas já utilizou aplicativos educacionais e que 34,6 \% já desenvolveu alguma atividade educacional com o uso de computadores.

Segundo Silva (2014) as discussões relativas ao uso de recursos tecnológicos estão em fase de consolidação, porém com um número de trabalhos bastante significativo de pesquisas e experiências sobre esse tema. Segundo o autor esses trabalhos conduzem à reflexão sobre os desafios da educação na formação das novas gerações, além de avaliar a importância das mídias na formação dos professores. Para Silva (2014, p.197):

"... é interessante avaliar a familiaridade dos docentes com recursos tecnológicos tais como telefones celulares, notebooks, tablets e, sobretudo com os programas interativos disponíveis para serem usados com estes aparatos. São objetivos prover elementos para que os docentes possam refletir sobre: os aspectos que afetam diretamente a implantação de recursos tecnológicos para o ensino; o papel pedagógico das mídias; e as transformações sociais, culturais e educacionais de nosso tempo ..."

Segundo Tyagi (2013) o número de dispositivos móveis, celulares, tablets e notebooks que se conectarão no planeta inteiro em 2014 tende a romper a marca de sete bilhões, potencializando as possibilidades das atividades que fazemos por meio destes dispositivos, sejam elas atividades comerciais, bancárias, de trabalho ou de aprendizagem. Para Tyagi (2013):

"... é quase impossivel ir a lugar nenhum sem esbarrar em um mar de pessoas que usam telefones celulares ou dispositivos equivalentes. Com o advento de novos dispositivos móveis, como smartphones, tablets e outros, a computação móvel atingiu a maioridade global, uma vez que o crescimento da web móvel não tem sinais de abrandamento. Em suma, os dispositivos móveis serão um elemento vital no desenvolvimento das próximas gerações, pois permitirão novas modalidades e processos de aprendizagem, ..."

Os resultados mostram que os futuros professores têm acesso amplo aos recursos tecnológicos, entretanto não os utilizam nas suas atividades de aprendizagem o que indica de maneira indireta que os cursos de Licenciatura não têm levado em conta o potencial das TICs no processo de ensino aprendizagem. Uma provável causa do pouco uso das TICs por parte dos alunos talvez seja a pouca aplicabilidade destas ferramentas nas disciplinas de seus cursos. Cabe assim uma análise mais criteriosa dos currículos dos cursos tendo por foco as ementas das disciplinas de modo a se identificar as potencialidades de uso das TICs durante os cursos.

$\mathrm{Na}$ internet são inúmeros os sítios de exemplos ou propostas de uso destas tecnologias nas mais diversas atividades de ensino e aprendizagem. Podemos destacar aqui, como exemplo o 
Horizon Report (2014) que é resultado de um projeto que tem mantido uma série contínua de conversas com centenas de profissionais de tecnologia, tecnólogos campus, líderes do corpo docente de faculdades e universidades, e representantes das principais corporações para explorar e prever o impacto de tecnologias emergentes em todos os setores de aprendizagem. Existem também uma enorme quantidade de sítios que indicam soluções para aplicações das TICs no ambiente escolar onde destacamos: Edudemic (2014), Universia (2014), Free Technology for Teachers (2014), Phet (2014), TED (2014), Scratch (2014) entre outros.

\section{Considerações finais}

O uso das TICs no ensino tem uma forte tendência de ser intensificado nos próximos anos, porém para a sua efetiva aplicabilidade é necessário a introdução dessa perspectiva na formação dos futuros docentes.

Esta pesquisa mostra que os alunos dos cursos de licenciatura já dispõem de uma significativa familiaridade com estas tecnologias, entretanto não têm como prática comum o uso desses recursos nas suas atividades de ensino-aprendizagem e aqueles que já estão na prática docente também utilizam as TICs de modo incipiente.

Cabe então aos cursos de graduação o estímulo para o uso das infinitas possibilidades de emprego das TICs no processo de ensino-aprendizagem, porém para que tal processo se efetive é necessário que se repense as grades curriculares dos cursos de modo que se possa integrar efetivamente as TICS ao cotidiano de estudo dos alunos.

Isso envolve um processo bastante complexo, pois deve em princípio modificar o procedimento dos formadores dos futuros professores. Talvez esteja ai o grande limitador temporal para a efetiva aplicabilidade e integração dos recursos tecnológicos ao cotidiano dos alunos em especial das licenciaturas.

Neste cenário temos os seguintes elementos: de um lado a necessidade, que se impõe de maneira mais intensa, a cada dia que passa, de uso das TICs na educação e de outro lado as dificuldades estruturais, que envolvem os currículos e as práticas dos formadores das IES que desconsideram a importância econômica e social das TICs como elemento de construção de capital social. Capital social aqui corresponde aos conhecimentos e atitudes dos indivíduos nas relações econômicas e sociais, nas quais as TICs já são onipresentes.

\section{Referências}

ALMEIDA, M.. Tecnologia de informação e comunicação na escola: aprendizagem e produção da escrita. Série Tecnologia e Currículo - Programa Salto para o Futuro, Novembro, 2001. Disponível 
em: <http://www.eadconsultoria.com.br/matapoio/biblioteca/textos_pdf/texto24.pdf>. Acesso em: julho de 2014.

CANIATO, R.. Interdisciplinaridade no ensino da ciência. In: SANTOS, C. A. dos e QUADROS, A. F. de (Orgs.). Utopia em busca de possibilidade: abordagens interdisciplinares no ensino das ciências da natureza. Foz do Iguaçu: UNILA, 2011. Cap. 3, p. 51-62.

CAXIAS, R. S.. Das tecnologias da informação à comunicação científica: críticas à nova cultura da pesquisa em educação. Em Questão, Porto Alegre, v. 14, n.2, p. 301-315, jul./dez. 2008.

EDUDEMIC. In: <www.edudemic.com>. Acesso em: julho de 2104

FREE TECHNOLOGY FOR TEACHERS. In: <http://www.freetech4teachers.com>. Acesso em: julho de 2104.

HORIZON REPORT. In: <http://www.nmc.org/horizon-project>. Acesso em: julho de 2104 INFANTE-MALACHIAS, M. E.. Interdisciplinaridade e resolução de problemas: algumas questões para quem forma futuros professores de ciências. In: SANTOS, C. A. dos e QUADROS, A. F. de (Orgs.). Utopia em busca de possibilidade: abordagens interdisciplinares no ensino das ciências da natureza. Foz do Iguaçu: UNILA, 2011. Cap. 6, p. 93-104.PHET. In:

<https://phet.colorado.edu>. Acesso em: julho de 2104

POMBO, O.. Para um modelo reflexivo de formação de professores. In: SANTOS, C. A. dos e QUADROS, A. F. de (Orgs.). Utopia em busca de possibilidade: abordagens interdisciplinares no ensino das ciências da natureza. Foz do Iguaçu: UNILA, 2011. Cap. 1, p. 13-36.

PORTO, T. M. E.. As tecnologias de comunicação e informação na escola; relações possíveis ... relações construídas. Revista Brasileira de Educação, v. 11, n. 31, p. 43-57, jan./abr. 2006.

SCRATCH. In: <scratch.mit.edu>. Acesso em: julho de 2104

SILVA, S. L. R da.. As novas tecnologias e a prática docente no parfor. In: PAINI, L. D.; COSTA, C. E. M. da e VICENTINI, M. R.. (Orgs). Parfor: integração entre universidade e ensino básico diante dos desafios na formação de professores do paraná. Maringá: EDUEM, 2014, p.195-212.

TAJRA, S. F.. Informática na educação: novas ferramentas pedagógicas para o professor na atualidade. 8 ed. São Paulo: Érica, 2008, p. 80-104.

TED. In: <www.ted.com>. Acesso em: julho de 2104

TYAGI, S.. How Mobile Learning Works. In: <http://www.edudemic.com/how-mobile-learningworks>. Acesso em: julho de 2014

UNIVERSIA. In: <www.universia.com.br> Acesso em julho de 2104

VILLANI, A. e MELGAÇO, J.. Revisitando experiências interdisciplinares no ensino de ciências. In: SANTOS, C. A. dos e QUADROS, A. F. de (Orgs.). Utopia em busca de possibilidade: abordagens 
interdisciplinares no ensino das ciências da natureza. Foz do Iguaçu: UNILA, 2011. Cap. 4, p. 6378.

Silvio Luiz Rutz da Silva - Doutor em Ciência dos Materiais (UFRGS), Professor do Departamento de Física e do Programa de Pós-graduação em Ensino de Física - Mestrado Nacional Profissional em Ensino de Física da Universidade Estadual de Ponta Grossa, UEPG-Ponta Grossa, Paraná.

E-mail: slrutz@gmail.com

Alan Vaz Mainardes - Licenciando em Ciências Biológicas na Universidade Estadual de Ponta Grossa, UEPG-Ponta Grossa, Paraná.

E-mail: alanmainardes@hotmail.com

Daniela Mayer Antunes - Licencianda em Ciências Biológicas na Universidade Estadual de Ponta Grossa, UEPG-Ponta Grossa, Paraná.

E-mail: daniela_mayerpg@hotmail.com

Letícia Polli Glugoski - Licenciada em Química (UEPG), Mestranda no Programa de Pós-graduação em Química Aplicada da Universidade Estadual de Ponta Grossa, UEPG-Ponta Grossa, Paraná.

E-mail: letypollig@hotmail.com

Patrícia Sattin Garrouba Biégas - Licenciada em Física (UEPG), Mestranda no Programa de Pósgraduação em Ensino de Ciência e Tecnologia da Universidade Federal Tecnológica do Paraná, UTFPR-Ponta Grossa, Paraná.

E-mail: patriciasattin@yahoo.com.br

Jéssica da Silva Gaudêncio - Mestranda no Programa de Pós-graduação em Ensino de Ciências da Universidade de São Paulo, USP-São Paulo, São Paulo.

E-mail: jessigaudencio@hotmail.com

DOI: Em andamento. 